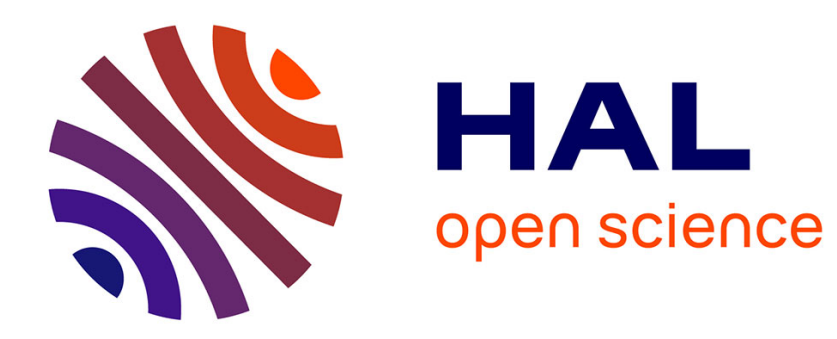

\title{
Débats scolastiques sur la dîme au XIIIe siècle Elsa Marmursztejn
}

\section{To cite this version:}

Elsa Marmursztejn. Débats scolastiques sur la dîme au XIIIe siècle. M. Lauwers. La dîme, l'Église et la société féodale, Brepols, pp.507-526, 2012. halshs-02951149

\section{HAL Id: halshs-02951149 https://shs.hal.science/halshs-02951149}

Submitted on 28 Sep 2020

HAL is a multi-disciplinary open access archive for the deposit and dissemination of scientific research documents, whether they are published or not. The documents may come from teaching and research institutions in France or abroad, or from public or private research centers.
L'archive ouverte pluridisciplinaire HAL, est destinée au dépôt et à la diffusion de documents scientifiques de niveau recherche, publiés ou non, émanant des établissements d'enseignement et de recherche français ou étrangers, des laboratoires publics ou privés. 


\title{
DÉBATS SCOLASTIQUES SUR LA DÎME AU XIII ${ }^{e}$ SIÈCLE $^{1}$
}

\author{
ELSA MARMURSZTEJN \\ CERHIC, Université de Reims - Institut Universitaire de France
}

$\mathrm{P}$

articipant d'une curiosité amplement déployée en dehors du champ spéculatif, les débats sur la dîme, que l'on abordera principalement ici du point de vue des théologiens du XIII ${ }^{\mathrm{e}}$ siècle, occupent une place importante dans les sources scolastiques. Ils y voisinent avec les discussions sur la cessation des legalia et sur les modes licites ou illicites de dévolution ou d'acquisition des biens, et en particulier des bénéfices ecclésiastiques. Ces débats témoignent en premier lieu de l'intérêt que les théologiens ont porté aux questions de l'institution et du régime juridique de la dîme. Ces questions ont constitué le point de départ d'une enquête exégétique et juridique en profondeur sur la persistance en tout ou partie du précepte vétérotestamentaire de la dîme, sur un terrain occupé en surface par les canonistes. Les théologiens se sont également attachés au problème de la contradiction entre le droit ecclésiastique exclusif qu'ils travaillaient à fonder ou à refonder et les cas $^{2}$ d'exemptions de fait, de variations locales de quotité, de détention de dîmes par des laïcs ou des religieux, de disjonction entre dîme et territoire paroissial, le travail casuistique permettant de rendre raison des exceptions qui forment le second volet du traitement scolastique de la question de la dîme. La scolastique articule donc méthodiquement des questions ecclésiologiques fondamentales (sur le rapport à la Loi ancienne ; sur l'appropriation et l'usage légitime des biens temporels par l'Église, dans un contexte marqué par le succès des ordres mendiants) et la question des relations d'échange et de conflit avec les laïcs, nouées par le couple spiritualia / temporalia dont Charles de Miramon a retracé la genèse entre Guillaume de Champeaux et Gratien ${ }^{3}$. Lié par la référence capitale à l'Épître aux Corinthiens - « Si donc nous avons semé parmi vous des biens spirituels, est-ce une grande chose que nous recueillions un peu de vos biens temporels? $\gg^{4}-$, ce

1. Cet article complète et élargit l'étude sur le traitement quodlibétique de la dîme que j'ai proposée dans L'Autorité des maîtres. Scolastique, normes et société au XIII siècle, Paris, 2007, p. 155-171; je me permets également de signaler l'édition des six questions quodlibétiques de Gérard d'Abbeville sur la dîme: E. MARMURSZTEJN, «Une contribution au débat scolastique sur la dîme au XIII ${ }^{\mathrm{e}}$ siècle: six questions quodlibétiques de Gérard d'Abbeville », Archives Doctrinales et Littéraires du Moyen Âge, 77, 2010, p. 107-156.

2. Qui relèvent de la contingence, de l'accident ou du cas d'école: Contingit, accidit, esto quod, disent les textes.

3. C. DE MiRAmON, «Spiritualia et Temporalia. Naissance d'un couple», Zeitschrift der SavignyStiftung für Rechtsgeschichte, 123, 2006, p. 224-287.

4. 1 Cor. $9,11$. 
couple est sans doute au cœur de la problématique scolastique de la dîme: si son union fait la norme, sa séparation met-elle le droit de l'Église en péril?

Du point de vue des sources, les débats sur la dîme manifestent la coexistence entre la communauté de méthodes et la diversité de formes, d'approches et d'opinions, qui caractérise la pensée scolastique. La dîme est mise « en questions » dans des sommes théologiques comme la Summa aurea de Guillaume d'Auxerre (dans les années 1220), la Somme franciscaine dite d'Alexandre de Halès (avant 1245) ou la Somme de théologie de Thomas d'Aquin (1271-1272 pour sa deuxième partie); elle l'est également dans des Quodlibets comme ceux de Gérard d'Abbeville dans les années 1260, des franciscains John Peckham et Roger Marston dans les années 1270-1280 ou des séculiers Henri de Gand et Godefroid de Fontaines dans la décennie suivante. L'effet de répétition produit par les références communes et les emprunts mutuels complique l'examen des textes. Issus d'un même stock, les casus sont raccrochés à des questions et à des raisonnements distincts. Au-delà des nuances, les divergences d'opinions affectent aussi bien les origines scripturaires de l'obligation de la dîme que le détail des cas. Le rapport au droit complique le débat. Les sources canoniques - que compilent, vers 1234, les seize chapitres sur la dîme de la Somme de pénitence du dominicain Raymond de Peñaforte - ont suscité et alimenté la réflexion théologique. Les questions très polémiques de la Summa aurea d'Hostiensis sur la dîme (vers 1253), récusant systématiquement les positions théologiques, forment un autre point d'appui important.

Après avoir suivi les voies diverses de l'enquête théologique sur l'institution de la dîme et sur la nature de l'obligation qui en découle, on considèrera la question de savoir à quels sujets et à quels territoires une telle obligation s'applique (soit, en l'espèce, la question de l'universalité et du caractère paroissial de la dîme), puis on analysera le traitement des exceptions pratiques (coutume contraire, concession de dîmes à des laïcs ou à des religieux), qui mettent la norme à l'épreuve et contribuent à en préciser la définition.

\section{ARCHÉOLOGIE D'UNE OBLIGATION : LA MISE AU JOUR D'UNE NORME CHRÉTIENNE}

L'origine vétérotestamentaire de la dîme déclenche une enquête à la fois exégétique et juridique, du fait de la scansion juridique de l'histoire du salut, souvent rappelée dans les textes théologiques sur la dîme: à l'époque antérieure à la Loi avaient succédé le temps de la Loi, puis le temps de la grâce. Effectuée dans les différentes couches du texte biblique, cette enquête relevait pleinement des compétences théologiques telles que les définit par exemple une question de la Somme d'Henri de Gand sur l'achèvement de la Révélation par le Nouveau Testament. Le maître séculier rappelait dans ce texte que la doctrine évangélique avait accompli la doctrine de l'Ancien Testament de deux façons : d'une part, par l'abolition de l'observance littérale et par l'interprétation spirituelle de l'obser- 
vance des cerimonialia; d'autre part, par le parachèvement des moralia, dont les lacunes avaient été comblées et l'application étendue: «Ainsi, la doctrine évangélique n'a pas tant consisté à accomplir qu'à exposer l'Ancien Testament (non tam erat impletiva quam expositiva), en expliquant la façon parfaite d'observer les préceptes légaux universels $»^{5}$. Les apôtres, qui avaient entrepris d'expliciter la doctrine évangélique (complète et parfaite en elle-même), avaient aussi continué d'interpréter les préceptes cérémoniels et de compléter les préceptes moraux, suivant «l'art d'expliquer les choses obscures et de suppléer les omissions » 6 , transmis par le message évangélique. À leur suite, les Pères, puis les docteurs, avaient pris place dans cette hiérarchie d'interprètes ${ }^{7}$. En l'occurrence, la question de la continuité de l'obligation d'acquitter la dîme sous le régime de la Loi nouvelle se compliquait du problème de la double nature de la dîme comme obligation indéterminée et comme proportion déterminée.

\section{$\underline{\text { L'institution de la dîme }}$}

On trouve chez Alexandre de Halès un passage original sur l'institution de la dîme, qui l'inscrit dans un processus de révélation de la nature du Sauveur et fait correspondre une offrande adéquate à chaque étape de cette révélation ${ }^{8}$ : nul ne pouvant être sauvé, après le péché, sans une foi implicite ou explicite envers le Sauveur', sa personne avait été révélée successivement dans sa nature divine de Conditor à Abel, qui l'avait honoré des prémices ${ }^{10}$; dans sa nature créée de Mediator qui se sacrifierait pour les hommes à Noé, qui l'avait honoré d'offrandes et de sacrifices ${ }^{11}$; dans sa nature humaine de Redemptor à Abraham ${ }^{12}$, qui l'honora de la dîme parce qu'elle désignait la nature humaine, d'après la parabole de la dixième drachme (Luc 15, 8-10) ${ }^{13}$. La dîme n'avait donc pas été instituée a principio (ce qui aurait été le cas si elle avait constitué un « remède au péché

5. Henri de Gand, Summa quaestionum ordinarium, a. 8, q. 6, Reprint of the 1520 Edition, t. 1, Newyork-Louvain-Paderborn, 1953, $\mathrm{f}^{\mathrm{O}}$ 69r.

6. Ibid

7. Ibid., $\mathrm{f}^{\mathrm{o}} 69 \mathrm{v}$.

8. Alexandre de Halès, Summa theologica, pars 2, inq. 3, tract. 2, q. 3 : De praeceptis iudicialibus circa decimas, primitias et oblationes, tit. 1: De decimis, cap. 1, Coll. S. Bonaventurae, Quarrachi, 1948, p. 729b-730a.

9. Cf. Augustin, In Ioan. Evang., II, hom. 34, n. 6 (PL 76, 1249) et Act. 4, 12.

10. Gn 4, 4: «Abel offrit aussi des premiers-nés de son troupeau, et de ce qu'il avait de plus gras. Et le Seigneur regarda favorablement Abel et ses présents ».

11. Gn 8,20 (après que les eaux se sont retirées): « Or Noé dressa un autel au Seigneur; et prenant de tous les animaux et de tous les oiseaux purs, il les lui offrit en holocauste sur cet autel ».

12. Gn 22, 9 (sacrifice d'Isaac).

13. «(8) Ou qui est la femme qui, ayant dix drachmes, et en ayant perdu une, n'allume la lampe et, balayant la maison, ne la cherche avec grand soin jusqu'à ce qu'elle la trouve, (9) Et après l'avoir retrouvée, elle appelle ses amies et ses voisines, et leur dit: Réjouissez-vous avec moi, parce que j'ai trouvé la drachme qui était perdue ? (10) Je vous dis de même que c'est une joie parmi les anges de Dieu, lorsqu'un seul pécheur fait pénitence ». 
originel ${ }^{14}$ ) mais par Abraham, parce que, comme l'avait dit Hugues de SaintVictor, « il fallait que, dans la succession des époques, les signes des grâces spirituelles gagnent en évidence, en sorte que la connaissance de la vérité croisse avec l'effet du salut $»^{15}$. La dîme marquait ainsi un terme dans le processus de révélation de la vérité; elle honorait adéquatement la nature humaine du Christ, comme les prémices honoraient le Créateur et les oblations le Médiateur. Abel, Abraham et Melchisédech étaient nommés dans le canon de la messe «parce que dans leur offrande était exprimée la personne du Sauveur ${ }^{16}$, et Melchisédech ${ }^{17}$ y était substitué à Noé parce qu'il n'avait pas offert une bête, suivant le rite de l'Ancienne Loi, mais du pain et du vin, préfigurant le rite de la Nouvelle Loi ${ }^{18}$.

L'enquête sur l'institution de la dîme comporte un volet sur la détermination de sa quotité. Correspondant, selon Guillaume d'Auxerre, à la taxation ${ }^{19}$ des onze tribus au profit des lévites et des prêtres (Nombres 18, 21-26) ${ }^{20}$, elle est également présentée par Thomas d'Aquin comme une «institution divine » conforme à la division en douze tribus du peuple auquel la Loi avait été donnée et à la nécessité d'entretenir la tribu des lévites, consacrée au ministère divin et dépourvue de possessions. En termes arithmétiques, l'institution n'est compréhensible que si l'on rappelle que Dieu avait ordonné à Moïse qu'un dixième de cette dîme fût versé par les lévites eux-mêmes aux prêtres descendants d'Aaron - ce qu'aucun des deux théologiens dominicains ne précise. Le don des lévites aux prêtres est évoqué par ailleurs ${ }^{21}$.

L'institution vétérotestamentaire de la dîme avait-elle été confirmée par la Nouvelle Loi? C'est l'opinion isolée que soutient Gérard d'Abbeville dans son premier Quodlibet:

Dic quod solutio decimarum fuit triplici lege instituta: primo in lege nature ex divina inspiratione; secundo in lege scripta, scilicet Moysi, ex divini pre-

14. Alexandre de Halès, Summa, tit. De decimis, cap. 1, cit. n. 8, p. 728b.

15. Ibid., p. 730a: [...] sicut dicit Hugo de S. Victore, in libro De sacramentis, oportuit, ut secundum successum temporum spiritualium gratiarum signa magis ac magis evidentia ad eam declarandam formarentur, ut cum effectu salutis cresceret cognitio veritatis.

16. [...] quia in oblatione istorum expressa est persona Salvatoris (Ibid.)

17. Gn 14, 18-20: «(18) Mais Melchisedech, roi de Salem, offrant du pain et du vin, parce qu'il était prêtre du Dieu très haut, (19) Bénit Abram, en disant : [...] (20) que le Dieu très haut soit béni, lui qui, par sa protection, vous a mis vos ennemis entre les mains. Alors Abram lui donna la dîme de tout ce qu'il avait pris ».

18. Ibid.

19. Taxavit Dominus in veteri Testamento decimam partem [...] (Guillaume d'Auxerre, Summa aurea, lib. 3, tr. 51, cap. 5, éd. J. RIBAILLIER, Paris-Grottaferrata, t. 18-2, 1986, p. 1007).

20. Dieu s'adresse à Aaron: «(21) Pour ce qui regarde les enfants de Lévi, je leur ai donné en propre toutes les dîmes d'Israël, pour les services qu'ils me rendent dans leur ministère au tabernacle de l'alliance [...] (25) Le Seigneur parla aussi à Moïse, et lui dit: (26) Ordonnez et déclarez aux Lévites: lorsque vous aurez reçu des enfants d'Israël les dîmes que je vous ai données, offrez-les en prémices au Seigneur, c'est-à-dire, la dixième partie de la dîme ».

21. Par exemple par Alexandre de Halès lorsqu'il traite la question de savoir si les clercs sont tenus d'acquitter la dîme, Summa, tit. De decimis, cap. 7, art. 2, cit. n. 8, p. 748. 
cepti expressa promulgatione; tertio in lege gratie, scilicet evangelii, ex Christi confirmatione ${ }^{22}$.

Le théologien lisait cette confirmation du précepte vétérotestamentaire dans l'Évangile de Matthieu (23, 23):

«Malheur à vous, scribes et pharisiens hypocrites, qui payez la dîme de la menthe, de l'aneth et du cumin, et qui avez abandonné ce qu'il y a de plus important dans la loi, savoir la justice, la miséricorde et la foi. C'étaient là les choses qu'il fallait pratiquer, sans néanmoins omettre les autres (haec oportuit facere, et illa non omittere) ».

Gérard d'Abbeville suivait sur ce point le canoniste Hostiensis, qui s'était luimême fondé sur un dossier d'autorités scripturaires incluant la citation de l'Évangile de Matthieu pour affirmer «qu'il faut acquitter les dîmes sur toutes choses, intégralement et en vertu d'un précepte, même si certains maîtres veulent comprendre et exposer ces autorités autrement $»^{23}$.

De fait, les théologiens ont très généralement considéré, à l'instar de Guillaume d'Auxerre, que la citation de l'Évangile de Matthieu non loquebatur nisi de Iudeis $^{24}$. Comme le dit très explicitement Thomas d'Aquin:

Non apparet in Novo Testamento aliquod preceptum datum de decimis solvendis, in doctrina, dico, evangelica vel apostolica: quod enim dicitur Mathei xxiii de solutione decimarum: "Hec oportuit facere et illa non omittere", et quod dicit Phariseus, Luce xviii: "Decimas do omnium que possideo", magis videtur ad statum Veteris Testamenti pertinere, quam observancie Novi Testamenti formam imponere ${ }^{25}$.

Henri de Gand clôt la question de savoir « si les dîmes sont de droit évangélique » en répondant précisément à l'argument constitué par la référence à Matthieu 23, 23 : Licet illud scriptum sit in Evangelio, non tamen Christus dixit illud pro tempore Evangelii, sed pro tempore legis Moysi ${ }^{26}$. Godefroid de Fontaines, enfin, récusait l'opinion des «juristes » qui fondaient l'obligation de la dîme sur un précepte divin: Ignoranter dicunt quidam iuristae quod decimae nunc sunt solvendae sicut etiam in veteri lege ex obligatione divini precepti ${ }^{27}$. La question se posait donc de savoir ce qui se conservait, sous le régime de la Loi nouvelle, de l'obligation vétérotestamentaire de la dîme.

22. Gérard d'Abbeville, Quodlibet I, 13, ms. BnF, lat. 16405, f 31 ra; Vatican, lat. 1015, fo 39vb.

23. Hostiensis, Summa aurea, éd. Lyon, 1556, f ${ }^{\circ} 253 \mathrm{va.}$

24. Per vetus Testamentum non potest probari quod christianus populus teneatur dare decimas, nec per Evangelium, quia, quando Dominus loquebatur de decimis, non loquebatur nisi de Iudeis (Guillaume d'Auxerre, lib. 3, tr. 51, cap. 3, cit. n. 19, p. 1000).

25. Thomas d'Aquin, Quodlibet II, 8, éd. R.-A. GAUTHIER, Rome, 1996, vol. 2, p. 224.

26. Henri de Gand, Quodlibet IV, 28, éd. Paris, 1518, $\mathrm{f}^{\circ} 145 \mathrm{r}^{\circ}$.

27. Godefroid de Fontaines, Quodlibet XI, 12, éd. J. HofFMANS, dans Les Quodlibets onze-quatorze de Godefroid de Fontaines, Louvain, 1932, p 61. 


\section{La nature de l'obligation sous le régime de la Loi nouvelle}

La question de savoir si la dîme relevait d'un précepte ou d'un conseil ${ }^{28}$ impliquait de distinguer entre son caractère indéterminé et son caractère déterminé. Selon Alexandre de Halès, l'obligation indéterminée de consacrer une part de ses revenus à l'entretien des ministres de Dieu avait toujours existé in praecepto et de iure naturae. La détermination du dixième, en revanche, ante Legem fuit in consilio, in Lege vero fuit in praecepto simpliciter. In tempore vero gratiae factae sunt in praecepto, cum necessitas est et petuntur a ministris, vel etiam si non petuntur, dum tamen sit consuetudo regionis ${ }^{29}$.

Que l'obligation indéterminée de la dîme, fondée en droit naturel et en raison, vaille sans distinction d'époque, relève de l'opinion théologique commune: c'est un « précepte » qui « quant à sa substance est inscrit dans le cour de l'homme $»^{30}$ (Guillaume d'Auxerre), qui procède de la « conscience $»^{31}$, de la « raison universelle » et « dans l'absolu du droit naturel $»^{32}$ (Alexandre de Halès), de la « raison naturelle $»^{33}$ (Thomas d'Aquin), du «droit naturel » et de «l'estimation de la droite raison $»^{34}$ (Henri de Gand), de « la nécessité du salut et d'un précepte de la loi naturelle $»^{35}$ (Godefroid de Fontaines).

Les maitres ont exprimé cette obligation générale selon différents registres. Ils l'ont naturalisée par la référence capitale à la première Épître aux Corinthiens $(9,11)^{36}$ : qui semait les spiritualia récoltait des temporalia. L'Épître filait ellemême la métaphore agricole:

«Qui est-ce qui plante une vigne et n'en mange point du fruit ${ }^{37}$ ? Ou qui est celui qui mène paître un troupeau et n'en mange point du lait? [...] En effet, celui qui laboure doit labourer avec espérance de participer aux fruits de la terre; et aussi celui qui bat le grain doit le faire avec espérance d'y avoir part $»^{38}$.

28. Posée dans ces termes par Alexandre de Halès (Summa, tit. De decimis, cap. 2, cit. n. 8, p 730-731) et reprise par Peckham dans le cadre plus large de l'obligation pour les laïcs d'acquitter la dîme: le don d'Abraham $(\mathrm{Gn} 4,5)$ ou le vœu de Jacob $(\mathrm{Gn} 28,20)$, du côté du conseil, sont notamment opposés aux citations du Lévitique $(27,32)$, des Nombres $(18,20)$ et de Matthieu $(23,23)$, du côté du «précepte » (John Peckham, Quodlibet IV, 50, éd. G. J. ETzKoRN et F. Delorme, dans Quodlibeta quatuor, Grottaferrata, 1989, p. 288).

29. Alexandre de Halès, Summa, tit. De decimis, cap. 2, cit. n. 8, p. 731b.

30. Guillaume d'Auxerre, Summa aurea, lib. 3, tr. 51, cap. 2, cit. n. 19, p. 995.

31. Alexandre de Halès, Summa, tit. De decimis, cap. 3, cit. n. 8, p. 732b.

32. Ibid., cap. 1, p. 728b.

33. Thomas d'Aquin, Summa theologiae, IIa IIae, q. 87, a. 1, éd. léonine, t. 9, 1897, p. 227.

34. Henri de Gand, Quodlibet IV, 28, cit. n. 26, $\mathrm{f}^{\circ} 145 \mathrm{r}^{\circ}$

35. Godefroid de Fontaines, Quodlibet XI, 12, cit. n. 27, p. 60.

36. «Si donc nous avons semé parmi vous des biens spirituels, est-ce une grande chose que nous recueillions un peu de vos biens temporels?»

37. 1 Cor. 9, 7; cité notamment par Thomas d'Aquin dans la Summa theologiae, IIa IIae, q. 87, a. 1, cit. n. 33, p. 227, au début de la responsio.

38. 1 Cor. 9,7 et 10 . 
Les maîtres ont également conçu la dîme comme la rétribution du service des prêtres dans une logique de compensation ou d'échange économique qu'illustrent chez Thomas d'Aquin les citations de l'Évangile de Luc (Dignus est operarius mercede sua $)^{39}$ et de l'Évangile de Matthieu (Dignus est operarius cibo suo $)^{40}$. Les conditions du juste échange sont précisées par Guillaume d'Auxerre, qui introduit l'argument du principe d'égalité en référence au modèle de «l'égalité de la manne » accordée par Dieu dans l'Exode ${ }^{41}$ : pour Guillaume d'Auxerre, l'ordinatio naturalis voulait que ceux qui semaient des spiritualia récoltent des carnalia, la ratio requise entre ce qui était donné et ce qui était reçu exigeant que les laïcs, qui amassaient plus de biens temporels, en donnent aux clercs qui en amassaient moins, ut aequalitas sit et possint vacari Legi Dei, que vacatio spiritualis est ${ }^{42}$. Cette opinion est répétée littéralement par Alexandre de Halès ${ }^{43}$, qui dit par ailleurs que la dîme est donnée principalement secundum rationem aequitatis mutuae distributionis, ut sit aequalitas dati et accepti inter seminantem spiritualia et dantem temporalia, secundum quod possibile est ${ }^{44}$. Enfin, Thomas d'Aquin met cette forme de « taxation » ${ }^{45}$ en parallèle avec la fiscalité laïque : « Le précepte des dîmes est moral en ceci que ceux qui vaquent pour tout le peuple au service divin sont entretenus par les contributions (stipendia) du peuple, de même que sont entretenus par le peuple ceux qui servent dans les autres offices de la chose publique $»^{46}$ et qui «veillent à l'utilité commune, à savoir les princes, les chevaliers et autres personnes de cette sorte ${ }^{47}$. Guillaume d'Auxerre avait luimême désigné les dîmes comme les tributa animarum destinés aux prélats, qui assuraient la garde et le soin des âmes (ad tuitionem animarum et curationem), « de même que les tributs sont donnés à César pour la garde des corps (ad tuitionem corporum) ${ }^{48}$. La dîme apparaît finalement comme la rétribution naturelle et équitable d'une fonction sociale ordonnée à l'utilité commune, dans un schéma triparti implicite.

39. Lc 10, 7, et non Matthieu 10 comme il l'indique (Thomas d'Aquin, Summa theologiae, IIa IIae, q. 87, a. 1 , ad 2, cit. n. 33, p. 227); même citation dans 1 Tim. 5, 18.

40. Mt 10, 10, et non Matthieu 7 comme il l'indique (Thomas d'Aquin, Quodlibet II, 8, cit. n. 25, p. 225).

41. Allusion sans référence à l'Exode 16, 16-18: (16) « Et voici ce que le Seigneur ordonna: Que chacun en ramasse ce qu'il lui en faut pour manger [...] (17) Les enfants d'Israël firent ce qui leur avait été ordonné; et ils amassèrent les uns plus, les autres moins. (18) Et l'ayant mesuré à la mesure du gomor, celui qui en avait plus amassé n'en eut pas davantage, et celui qui en avait moins préparé n'en avait pas moins ».

42. Guillaume d'Auxerre, Summa aurea, lib. 3, tr. 51, cap. 6, cit. n. 19, p. 1009.

43. Alexandre de Halès, Summa, tit. De decimis, cap. 8, cit. n. 8, p. 750b-751a.

44. Ibid., cap. 3 , cit. n. 8 , p. 732 b.

45. Le terme est notamment employé par Guillaume d'Auxerre, Alexandre de Halès, John Peckham.

46. Thomas d'Aquin, Quodlibet II, 8, cit. n. 25, p. 225 : [...] ut scilicet qui pro toto populo divino obsequio vacant, stipendiis populi sustententur, sicut et qui in aliis officiis rei publice serviunt, a populo sustentantur.

47. ID., Summa theologiae, cit. n. 33, p. 227: [...] sicut et his qui communi utilitati invigilant, scilicet principibus et militibus et aliis huiusmodi, stipendia victus debentur a populo.

48. À l'occasion d'une question sur sa perception par les bénédictins (Guillaume d'Auxerre, Summa aurea, lib. 3, tr. 51, cap. 4, cit. n. 19, p. 1003). 
La raison naturelle qui fondait l'obligation générale de rétribution des ministres de l'Église ne pouvait toutefois en dicter la quotité précise:

Quamvis autem in corde hominis scriptum sit quod de propria substantia honorandus sit Deus et sustentandus minister eius, non tamen scriptum est de quota parte, ut nec de prima vel decima sicut nec de secunda vel tertia ${ }^{49}$.

Les théologiens ont résolu cette difficulté en forgeant le concept de précepte mixte: Guillaume d'Auxerre avait souligné que le précepte n'était pas purement moral, puisqu'il ne l'était pas quantum ad taxationem ${ }^{50}$ et que sa détermination incombait à l'Église. Thomas d'Aquin formule le concept de precepta media ${ }^{51}$ : ces préceptes «moyens » ne sont ni purement moraux, ni purement cérémoniels ou judiciels ${ }^{52}$, la dîme procédant « pour partie du droit naturel, pour partie d'une institution de l'Église $»^{53}$. L'expression de precepta mixta apparaît chez Henri de Gand: l'avènement de la loi évangélique avait fait cesser l'obligation des dîmes pro quota illa, mais elle demeurait pro illo quod erat de iure legis naturae ${ }^{54}$; la dîme n'était pas due à l'Église en vertu de la loi mosaïque, mais du fait d'une « nouvelle institution de l'Église »; elle relevait donc pour partie du droit naturel, pour partie du droit positif 55 .

\section{La question de la persistance de la quotité}

Cette question a donné lieu à des opinions graduées. Dans l'optique continuiste de Gérard d'Abbeville, la quotité du dixième signifiait, in lege evangelii, la soumission envers Dieu, l'accomplissement moral du Décalogue, la perfection dans les œuvres de charité, la restauration de l'ordre décimal ${ }^{56}$.

Dans une optique générale différente, les franciscains Alexandre de Halès ou John Peckham ont néanmoins donné des justifications fortes de la persistance de la quotité de la dîme au temps de la grâce. Pour Alexandre de Halès ${ }^{57}$, l'obligation déterminée ne relevait pas du droit naturel simpliciter, mais elle en relevait

49. Alexandre de Halès, Summa, tit. De decimis, cap. 1, cit. n. 8, p. 728a.

50. Guillaume d'Auxerre, Summa aurea, lib. 3, tr. 51, cap. 3, cit. n. 19, p. 1001: In omni iure preceptum est de decimis, sed indeterminatum est, et relinquitur determinatio arbitrio Ecclesie; preceptum de decimis non est pure morale, quia non est morale quantum ad taxationem.

51. Thomas d'Aquin, Quodlibet II, 8, cit. n. 25, p. 225.

52. Ibid., p. 226.

53. ID., Summa theologiae, cit. n. 33, p. 227.

54. Henri de Gand, Quodlibet IV, 28, cit. n. 26, $\mathrm{f}^{\mathrm{o}} 145 \mathrm{r}$.

55. Ibid.

56. Gérard d'Abbeville, Quodlibet I, 14, ms. BnF, lat. 16405, f ${ }^{\circ} 31 \mathrm{rb}$; Vatican, lat. 1015, $\mathrm{f}^{\mathrm{o}}$ 40rb: In lege autem evangelii debentur decime sub ratione talis quote, scilicet decime, quadriplici ratione, videlicet ratione signi, precepti, obsequii, commodi. Institute enim fuerunt ob significationis veritatem, propter precepti divini necessitatem, propter obsequii divini equitatem, propter temporalem et spiritualem commoditatem sive utilitatem [...]

57. Alexandre de Halès, Summa, tit. De decimis, cap. 1, cit. n. 8, p. 729. 
néanmoins secundum quid ${ }^{58}$. Dans son Quodlibet romain de $1277^{59}$, Peckam opposait, à l'idée du caractère purement cérémoniel de la quotité, les « préceptes du Siège Apostolique » contenus au titre De decimis du Liber Extra ${ }^{60}$. Il reprenait, dans un cadre différent, l'idée d'Alexandre de Halès selon laquelle le dixième était dû parce qu'il était «l'offrande de l'homme qui est la dixième drachme, comme le dit Luc 15, 8, et signifie la rédemption ». L'argument numérique (de la perfection du dixième ${ }^{61}$ ) justifiait que l'on attribuât à Dieu sa perfection et que l'on retînt l'imperfection - chose plus nécessaire dans le Nouveau que dans l'Ancien Testament, dit Peckham: Igitur modo debet dari decima sicut tunc, immo certe multo magis quanto perfectius est Novum Testamentum Veteri ${ }^{62}$.

En contrepoint, Thomas d'Aquin justifiait les variations de la quotité par le pouvoir même de l'Église: parce qu'elle avait le pouvoir de légiférer en matière de culte divin, l'Église pouvait fixer la quotité de ce qui serait versé à ses ministres et c'est «pour qu'il y ait quelque consonance entre l'Ancien et le Nouveau Testament, [qu']elle avait décrété que la taxation de l'Ancien Testament serait observée aussi dans le Nouveau ${ }^{63}$. Mais elle pouvait aussi bien décider, en fonction des époques et des personnes, qu'une autre quotité lui soit versée ${ }^{64}$.

La question des fondements de la dîme comme obligation générale découlant du droit naturel s'articule avec celles de l'universalité et de la territorialité de la dîme, que les scolastiques ont traitées dans une optique strictement casuistique.

\section{UNIVERSALITÉ ET TERRITORIALITÉ DE LA DÎME}

\section{La question de l'universalité de la dîme}

L'universalité de l'obligation est mise à l'épreuve de cas limites : celui des juifs, celui des pauvres, celui des clercs eux-mêmes.

La question de savoir si les juifs devaient acquitter la dîme - alors même qu'ils ne recevaient pas de spiritualia - a donné lieu à des solutions convergentes, exception faite de celle d'Henri de Gand. Gérard d'Abbeville se fonde sur la définition réelle des dîmes produite par la décrétale De terris: les dîmes prédiales $^{65}$ étaient dues indistincte, parce qu'elles portaient sur les terres et non sur les personnes. Selon Raymond de Peñaforte, cette règle s'imposait même à un

58. Ibid., p. 728 b.

59. John Peckham, Quodlibet IV, 50, cit. n. 28, p. 288-290.

60. Ibid., p. 289: [...] Quantum vero ad taxationem partis, erat caeremoniale mandatum; et caeremoniae cessaverunt. Sed illud est expresse contra praecepta Sedis Apostolicae, sicut patet Extra, De decimis.

61. Invoqué par ailleurs par Gérard d'Abbeville comme par Alexandre de Halès.

62. John Peckham, Quodlibet IV, 50, cit. n. 28, p. 289.

63. Thomas d'Aquin, Quodlibet II, 8, cit. n. 25, p. 226.

64. ID., Summa theologiae, IIa IIae, q. 87, a. 1, cit. n. 33, p. 227 (fin de la responsio).

65. Portant sur les produits du sol et le croît des animaux. 
invasor $^{66}$; Hostiensis ajoute: etiam Iudaeo, haeretico vel pagano ${ }^{67}$. Alexandre de Halès suit également cette ligne juridique à propos des dîmes prédiales en englobant les peccator et Iudeus et invasor ${ }^{68}$. Guillaume d'Auxerre n'évoquait pas les juifs, mais les usuriers, qui devaient les dîmes prédiales ratione predii, l'usure ne créant pas d'incapacité ${ }^{69}$. C'est précisément cette position que conteste Henri de Gand dans un Quodlibet de 1289 ou $1290^{70}$. Il y affirme que « les juifs et les autres usuriers » ne possèdent rien qui ne leur vienne de l'usure et qui ne doive par conséquent être restitué. Sauf nécessité matérielle extrême, l'Église ne devait pas empêcher cette restitution en exigeant la dîme. À l'argument qui déniait au prêtre le droit d'exiger des temporalia des juifs auxquels il n'administrait pas de spiritualia, Henri de Gand répond que les juifs auraient dû les acquitter s'ils avaient possédé quelque chose en propre, quia hoc non est debitum personale sed reale $^{71}$. En l'occurrence, la divergence n'affecte pas le principe de la norme; elle naît dans le détail des cas.

La question de savoir si les pauvres devaient la dîme à un prêtre riche semble ouvrir une seconde brèche dans la logique rétributive dictée par la raison naturelle. Or sur ce point théologiens et canonistes s'accordent totalement: les canonistes $^{72}$ affirmaient qu'un prêtre riche ne péchait pas en exigeant la dîme des pauvres s'il accomplissait convenablement son ministère et n'employait pas les dîmes à mauvais escient, mais au profit des pauvres. Dans le cas contraire, il était sacrilège; et si des gens mouraient de faim parce qu'il en avait reçu la dîme, précise Raymond de Peñaforte, il était coupable d'homicide ${ }^{73}$. Alexandre de Halès formule la même opinion, mais en termes strictement théologiques : « Les pauvres comme les riches doivent la dîme, qui est la part due à Dieu, dont le pauvre comme le riche reçoit tout ${ }^{74}$; le maître franciscain ajoutait la promesse d'abondance liée au versement des dîmes (d'après Malachie 3, $10^{75}$ et Augustin $^{76}$ ) et le parallèle

66. Ad praediales autem solvendas tenetur quilibet indisctincte, etiam invasor (Raymond de Peñaforte, Summa de paenitentia, lib. 1, tit. 15, cap. 6, éd. X. OCHOA et A. DIEZ, 1976, col. 417).

67. Praediales indisctincte solvi debent a possidente praedia, non solum iusto, sed a violento vel clandestino; non solum catholico, sed etiam Iudaeo, haeretico vel pagano (Hostiensis, Summa aurea, cit. n. 23, f $252 \mathrm{rb}$ ).

68. Alexandre de Halès, Summa, tit. De decimis, cap. 4, art. 1, cit. n. 8, p. 734b.

69. Guillaume d'Auxerre, lib. 3, tr. 51, cap. 3, cit. n. 19, p. 1002.

70. Henri de Gand, Quodlibet XIII, 16, éd. J. DECORTE, dans Henrici de Gandavo Opera omnia, t. 18, Louvain-Leyde, 1985, p. 203-204.

71. Ibid., p. 204.

72. Geoffroi de Trani, Raymond de Peñaforte ou Hostiensis.

73. Raymond de Peñaforte, Summa de Paenitentia, lib. 1, tit. 15, cit. n. 66, col. 422-423; Hostiensis, Summa aurea, cit. n. 23, f ${ }^{\circ}$ 253ra. Dans le Décret, la responsabilité de la mort des pauvres était assignée à ceux qui ne payaient pas la dîme qu'ils devaient (Decretum Grat., C. 16, q. 1, c. 66, Fr. 784).

74. Alexandre de Halès, Summa, tit. De decimis, cap. 1, cit. n. 8, p. 748.

75. «Apportez toutes mes dîmes dans mes greniers, et qu'il y ait dans ma maison de quoi nourrir mes ministres; et, après cela, considérez ce que je ferai, dit le Seigneur; si je ne vous ouvrirai pas toutes les sources du ciel, et si je ne répandrai pas ma bénédiction sur vous, pour vous combler d'une abondance de toute sorte de biens ».

76. Decretum Grat. C. 16, q. 7, c. 8 (Fr. 802). 
avec le «cens de César », dont les pauvres n'étaient pas exemptés. L'argument de l'entretien des pauvres par le prêtre, procurator pauperum ${ }^{77}$, n'est invoqué que dans les réponses aux objections. En termes singuliers, Thomas d'Aquin ${ }^{78}$ présente le devoir de rendre la dîme comme un «acte de justice », laquelle ne varie pas suivant la condition des personnes («celui qui achète quelque chose doit payer ce qu'elle vaut, qu'il soit riche ou pauvre $\left.{ }^{79}\right)$. Ce devoir, fondé sur le droit naturel, le droit divin (Dominus ordinavit hiis qui evangelium annunciant, ut de evangelio vivant ${ }^{80}$ ) et sur un statut de l'Église, devait être accompli par les pauvres, même envers des prêtres riches ${ }^{81}$. Thomas d'Aquin rappelle néanmoins que les dîmes étaient également destinées à l'entretien des pauvres et laisse ouverte la possibilité de ne pas les exiger, là où la coutume contraire risquait d'engendrer le scandale ${ }^{82}$. Au total, le produit des dîmes devaient bénéficier aux pauvres par l'intermédiaire des prêtres qui seuls les détenaient de droit, puisque ce droit était lié à la prestation de spiritualia.

Enfin, seul Thomas d'Aquin semble avoir tenu une position claire sur la question de savoir si les clercs eux-mêmes devaient acquitter la dîme. La question ne visait pas ce que les clercs possédaient au titre de l'Église, puisque c'est en raison de leur ministère qu'ils percevaient eux-mêmes la dîme des laïcs, comme l'ont fait observer Alexandre de Halès ${ }^{83}$ ou Thomas d'Aquin :

«Les dîmes sont dues par les fidèles aux clercs en tant que ministres de l'autel semant des spiritualia pour le peuple. C'est pourquoi ces clercs, en tant que tels, c'est-à-dire en tant qu'ils ont des possessions ecclésiastiques, ne sont pas tenus d'acquitter de dîmes $»^{84}$.

La question visait les biens propres des prêtres. Alexandre de Halès ${ }^{85}$ reproduit sur ce point le petit Sic et non de Raymond de Peñaforte ${ }^{86}$ :

«Certains disent qu'ils doivent [...] la dîme de leurs biens fonciers, patrimoniaux ou acquis, à l'église à laquelle elle était due avant que ces biens n'entrent en leur possession. D'autres distinguent selon qu'ils desservent ou non l'église à laquelle sont dues ces dîmes. Si c'est le cas, ils disent qu'ils n'y sont pas tenus; sinon, ils les doivent $\gg^{87}$.

77. Alexandre de Halès, Summa, tit. De decimis, cap. 6, cit. n. 8, p. 746b et cap. 7, Ibid., p. 748b.

78. Thomas d'Aquin, Quodlibet VI, 10, éd. R.-A. GAUTHIER, Rome, 1996, vol. 2, p. 304-305.

79. Ibid., p. 305.

80. 1 Cor. 9, 14; cité dans Thomas d'Aquin, Quodlibet VI, 10, cit. n. 78, p. 305.

81. Unde, cum sacerdotibus decime debeantur tum ex iure naturali tum de iure divino tum etiam ex statuto ecclesie, quamvis sacerdos sit dives, nichilominus pauper tenetur ei decimas solvere (Ibid.)

82. Ibid.

83. Alexandre de Halès, Summa, cap. cit. n. 8, p. 748b.

84. Thomas d'Aquin, Summa theologiae, IIa IIae, q. 87, a. 4, cit. n. 33, p. 232.

85. Alexandre de Halès, Summa, tit. De decimis, cap. 7, art. 2 (Utrum clerici teneantur ad decimas), cit. n. 8, p. 748-749.

86. Raymond de Peñaforte, Summa de paenitentia, lib. 1, tit. 15, cap. 2, cit. n. 66, col. 413.

87. Alexandre de Halès, Summa, tit. De decimis, cap. 7, cit. n. 8, p. 749a. 
Seul Thomas d'Aquin tranche, en explicitant la position de la glose ordinaire du Liber extra ${ }^{88}$ : s'ils «possèdent des biens fonciers proprio iure sur le territoire d'une église paroissiale, par héritage ou par achat ou de quelque manière que ce soit, ils sont obligés de verser les dîmes » - et ce, même s'ils sont clercs de cette église, quia aliud est habere aliquid ut proprium, aliud ut commune ${ }^{89}$.

Au total, l'universalité de la dîme se trouvait doublement fondée: comme droit spirituel dont le prêtre était fonctionnellement le sujet, elle englobait les pauvres; comme taxation foncière dont l'église paroissiale était bénéficiaire, elle était confirmée a fortiori par son extension aux biens des juifs et aux biens propres des clercs.

\section{Dîmes paroissiales, dîmes personnelles}

La question de la territorialité de la dîme peut être envisagée à travers celle de son caractère paroissial et foncier. Le caractère paroissial de la dîme est mis à l'épreuve des cas où, comme le dit Thomas d'Aquin, « on ne semble pas pouvoir distinguer à quel clerc il faut donner la dîme ${ }^{90}$. Trois cas - empruntés au droit canon $^{91}$ - sont envisagés : celui où l'on reçoit les sacrements dans une paroisse et où l'on cultive la terre dans une autre; celui où l'on fait paître son bétail à mitemps sur le territoire d'une paroisse, à mi-temps sur le territoire d'une autre; celui où le bétail, gardé dans une paroisse, paît sur le territoire d'une autre.

Les solutions d'Alexandre de Halès et de Thomas d'Aquin suivent celles de Raymond de Peñaforte et de la glose ordinaire des décrétales ${ }^{92}$. Raymond de Peñaforte distingue entre dîmes personnelles (dues à l'église ubi audit divina et recipit ecclesiastica sacramenta ${ }^{93}$ ) et dîmes prédiales (acquittées envers l'église de la paroisse où les terres sont situées, sauf certa consuetudo ${ }^{94}$ ). Dans le cas où le bétail paît dans une paroisse et est gardé dans une autre, la dîme doit aller à

88. Gl. Clericis ad Extra, 3, 30, 2, éd. Turin, 1588, col. 1357: Hoc intellige de dote ecclesiae de qua clerici non debent dare decimas, ut 16, q. 1, Questi [C. 16, q. 1, c. 46] Sed de praediis propriis sive patrimonialibus, clerici debent solvere decimas, ut 16, q. 1, Si quis laicus [C. 16, q. 1, c. 42]; et hoc sive praedia sint in propria parochia clericorum, sive in aliena.

89. Thomas d'Aquin, Summa theologiae, IIa IIae, q. 87, a. 4, $1^{\text {um }}$, responsio et ad $1^{\text {um }}$, cit. n. 33, p. $232-233$.

90. Ibid., q. 87, a. 3, $2^{\text {um }}$, p. 231.

91. Notamment Liber Extra, lib. 3, tit. 30, cap. 18 et 20 (Fr. 562).

92. Gl. Diversae ad Extra, 3, 30, 18, v., éd. Turin, 1588, col. 1366: Quidam enim ibi dicunt dandas esse decimas, ubi recipiuntur ecclesiastica sacramenta, supra eo Novum genus [Liber Extra lib. 3, tit. 30, cap. 2], et 16, q. 1, Questi. Alii dicunt, quod ibi debent dari, ubi praedia sita sunt, supra eodem Quoniam, et supra de paro. c. ult. et 16, q. 1, Si quis laicus. Sed facile est solvere hanc diversitatem: ibi debent dari personales decimae, ubi qui recipit ecclesiastica sacramenta, et si habet praedia in alia parochia, ibi debet dare decimas illorum praediorum. Si habet praedia in eadem parochia ubi audit divina, ibi debet dare decimas praediales et personales, et sic diversitas illa potest intelligi, nisi consuetudo prescripta sit contraria, ut dicit hic Bern.

93. Raymond de Peñaforte, Summa de paenitentia, lib. 1, tit. 15, cap. 9, cit. n. 66, col. 422.

94. Ibid. Peñaforte précise qu'en cas de doute sur la coutume, les dîmes prédiales doivent être données à l'église baptismale, les dîmes personnelles à la chapelle où l'on assiste au service divin. 
l'église de la paroisse où se situent les terres dont les bêtes tirent leur nourriture ${ }^{95}$. Alexandre de Halès répète les solutions du canoniste ${ }^{96}$, puis répond par le « droit commun » au cas des agneaux paissant à mi-temps dans deux paroisses: cum renovatio fiat in duabus parochiis, duobus sacerdotibus debet dari decima ${ }^{97}$. Thomas d'Aquin suit, sans aucune référence explicite au droit ${ }^{98}$.

Guillaume d'Auxerre avait en revanche pris une position singulière, d'abord en donnant une version divergente du « droit commun », suivant lequel, disait-il, le fidèle devait la dîme au prêtre qui lui administrait les spiritualia plutôt qu'à celui de la paroisse où il cultivait la terre ${ }^{99}$; ensuite en affirmant la nécessité de tenir compte des cas:

«Dans un cas raisonnable, l'Église peut [...] décider que la laine soit donnée au prêtre dans la paroisse duquel les moutons sont tondus [plutôt qu'aux deux prêtres] si l'autre église est riche; de même, le paysan doit donner la dîme au seul prêtre du territoire où il cultive si l'autre église est riche, en sorte qu'il y ait égalité dans la manne, comme on l'a dit ${ }^{100}$.

Ces divergences fortes s'expliquent sans doute par l'incertitude même du législateur, qui n'avait pas tranché la question soulevée par le cas de disjonction entre paroisse de réception des spiritualia et paroisse d'exploitation agricole. La décrétale d'Alexandre III insérée au Liber extra exprime en effet son embarras face à la « diversité » des autorités des Pères et renvoie, dans le doute, à la coutume: non est nobis facile super hoc certum dare responsum, quum auctoritates sanctorum Patrum etiam sint diversae. Et ideo in huiusmodi dubitatione ad consuetudinem duximus recurrendum ${ }^{101}$.

Quant à l'assise foncière de la dîme, elle est mise en cause par l'existence, à côté des dîmes prédiales, des dîmes personnelles. Ces dîmes intéressent directement les maîtres. Elles posent en outre le problème des revenus d'origine illicite (issus de la prostitution, de l'usure, du vol, etc.). Thomas d'Aquin propose à nouveau une solution tranchée: à l'instar d'Alexandre de Halès, qui notait que dans les cités dont les habitants n'avaient pas de possessions foncières, les ministres de l'Église seraient réduits à mendier s'ils ne percevaient pas de dîmes personnelles ${ }^{102}$, Thomas d'Aquin propose une justification rationnelle fondée sur des considérations historiques, démographiques et économiques: aucun précepte vétérotestamentaire

95. Ibid.

96. Le cas de disjonction entre paroisse d'habitation et paroisse d'exploitation agricole et le cas des agneaux paissant dans une paroisse et gardés dans une autre sont traités dans Alexandre de Halès, Summa, tit. De decimis, cap. 6, cit. n. 8, p. 745 b et 746 b.

97. Ibid., p. 746a.

98. Thomas d'Aquin traite les trois cas (Summa theologiae, IIa IIae, q. 87, a. 3, ad $2^{\text {um }}$, cit. n. 33, p. 232).

99. Similiter in secundo casu [de illo, qui habitat in una parochia et collit terram in alia], secundum ius commune, agricola debet dare decimas pastori suo, qui seminat spiritualia (Guillaume d'Auxerre, Summa aurea, lib. 3 , tr. 51, cap. 6, cit. n. 19, p. 1012).

100. Ibid.

101. Liber Extra, lib. 3, tit. 30, cap. 18 (Fr. 562).

102. Alexandre de Halès, Summa, tit. De decimis, cap. 4, a. 2, cit. n. 8, p. 735 b. 
n'avait institué de dîmes personnelles parce que les dîmes des tribus suffisaient à l'entretien des lévites; en revanche, «le peuple de la nouvelle loi », répandu par toute la terre, vivait largement d'occupations non-agricoles qui, si elles n'étaient pas taxées, ne contribueraient pas à l'entretien des ministres de Dieu. «C'est pourquoi sous la nouvelle loi les hommes sont tenus d'acquitter des dîmes personnelles, en fonction de la coutume de la patrie et de l'indigence des ministres ${ }^{103}$.

Or, comme l'indique Roger Marston dans une question quodlibétique de $1283^{104}$ vraisemblablement inspirée d'un casus de Jean le Teutonique ${ }^{105}$, ces dîmes étaient rarement exigées, sauf en Angleterre, parce qu'elles relevaient - suivant Geoffroi de Trani ${ }^{106}$ - d'un «statut humain » et du «droit positif », qu'abrogeait la «coutume locale approuvée ». C'est pourquoi Roger Marston hésitait à affirmer que les médecins et les avocats devaient la dîme de leur salaire, et les maîtres celle de leur collecta (non audeo asserere quod ad eas teneantur) ${ }^{107}$, privilégiant l'opinion de Geoffroi de Trani contre celle de Jean le Teutonique, l'un et l'autre nommément cités. Un demi-siècle auparavant, Raymond de Peñaforte avait exprimé l'hésitation contraire, « redoutant d'affirmer (definire) » que si les dîmes personnelles procédaient d'un «précepte humain », « ceux qui ne les acquittaient pas semblaient libérés de la faute par la coutume contraire », et se bornant au «conseil » de les verser, soit en vertu de l'autorité de l'évêque et des églises auxquelles elles seraient dues, soit en même temps que les aumônes quotidiennes à l'usage des pauvres ${ }^{108}$.

Quant aux revenus d'origine illicite, l'opinion prévaut ${ }^{109}$ - à nouveau contre Jean le Teutonique ${ }^{110}$ - que l'Église ne devait les soumettre à la dîme que dans les cas où la propriété de l'argent était effectivement transférée à celui qui l'avait gagné et n'exigeait donc pas qu'il le restitue, et à la condition expresse que le

103. Thomas d'Aquin, Summa theologiae, IIa IIae, q. 87, a. 2, ad $1^{\text {um }}$, cit. n. 33, p. 230.

104. Roger Marston, Quodlibet III, 20, éd. G. J. ETZKORN, I. BRADY, dans Quodlibeta quatuor, Quaracchi, 1968, p. 349-351.

105. G1. ad Decretum Grat., C. 16, q. 1, c. 66: Sed nunquid doctor de collecta, vel advocatus de patrocinio, vel mercenarius de eo quod meretur, dabit decimam? Non videtur, cum illud non sit lucrum, sed debitum. Credo tamen quod sic, quia scriptum est: Honorabis dominum Deum tuum de tuis iustis laboribus, ut 1, q. 1, Non est putanda. Item, quia hic dicitur, de omni artificio dandae sunt decimae, ut ext. eo., Non est in potestate.

106. Geoffroi de Trani, Summa super titulis Decretalium, ms. Paris, BnF, lat. 12453, fo 82rb. Disciple d'Azon, Geoffroi de Trani enseigna le droit romain à Naples. Auditeur de la Rote en 1240, il devint cardinal en 1244, à l'instigation d'Innocent IV. Il composa le premier commentaire complet sur les Décrétales de Grégoire IX avant 1243. Il le récrivit entièrement, avant sa mort en 1245, sous le titre de Summa super titulis Decretalium.

107. Roger Marston, Quodlibet III, 20, cit. n. 104, p. 350.

108. Raymond de Peñaforte, Summa de paenitentia, lib. 1, tit. 15, cap. 13, cit. n. 66, col. 426.

109. Ibid., cap. 6, cit. n. 66, col. 415-416; Alexandre de Halès, Summa, tit. De decimis, cap. 4, a. 1, cit. n. 8, p. 734b; Thomas d'Aquin, Summa theologiae, IIa IIae, q. 87, a. 2, ad 2um, cit. n. 33, p. 230.

110. Gl. ad Grat. C. 16, q. 1, c. 66, éd. Turin, 1588, col. 1333 : Dico quo a fure vel a raptore bene petitur decima, non ratione negociationis suae, cum illa sit reprobata, sed quia invenitur in possessione, quia decima sequitur quemlibet possessorem sive Iudaeum, sive excommunicatum, ut ext. de deci. De terris [...] Alioquin esset praedo melioris conditionis quam bonae fidei possessor. 
fidèle ait préalablement fait pénitence - sauf à sembler approuver les prostituées et les histrions ; comme le dit Alexandre de Halès, suivi de très près sur ce point par Thomas d'Aquin: Si vero transfertur dominium, tenetur dare, sed Ecclesia non debet recipere, quamdiu illa persona illa est in scelere, ne videatur eius approbare delictum $^{111}$.

Le cas mixte du champ acheté ou semé avec les fruits de l'usure est abordé dans le même mouvement: comme Alexandre de Halès, Thomas d'Aquin considère qu'un champ acheté avec des revenus usuraires doit être soumis à la dîme, car ses fruits ne proviennent pas ex actione usurarii, sed ex divina largitate et opere, quo multiplicatur semen (Alexandre de Halès) ${ }^{112}$, quia fructus illi non sunt ex usura, sed ex Dei munere (Thomas d'Aquin) ${ }^{113}$.

\section{EXCEPTIONS : \\ EXEMPTIONS, CONCESSION DE DÎMES À DES LAÏCS OU À DES RELIGIEUX}

\section{Divergences sur les exemptions coutumières}

Sans surprise, la coutume de ne pas acquitter de dîmes est rejetée par Gérard d'Abbeville, dont l'opinion est à nouveau conforme à celle d'Hostiensis : la coutume, dit le théologien, n'est pas conforme à la raison puisqu'elle s'oppose à la vérité naturelle, c'est-à-dire à l'ordre divin d'acquitter les dîmes; elle ne peut s'acquérir par prescription, qui en matière de dîmes ne peut bénéficier à des laïcs ; elle n'est pas non plus garantie par la tolérance de l'Église, car seule vaut l'approbation pontificale ${ }^{114}$. Thomas d'Aquin et Godefroid de Fontaines privilégient en revanche la considération d'un état de fait: selon Thomas d'Aquin, il eût été trop rigoureux de dire (durum esset dicere) que tous les hommes d'Italie et d'Orient ${ }^{115}$ étaient damnés et que les recteurs d'églises agissaient mal lorsque, par crainte du scandale, ils ne réclamaient pas les dîmes là où l'on n'avait pas coutume de les acquitter; en l'espèce, la dissimulatio ${ }^{116}$ de l'Église valait exemption ${ }^{117}$. Ce

111. Alexandre de Halès, Summa, tit. De decimis, cap. 4, a. 1, cit. n. 8, p. 734b.

112. Ibid.

113. Thomas d'Aquin, Summa theologiae, IIa IIae, q. 87, a. 2, ad 2um, cit. n. 33, p. 230.

114. Gérard d'Abbeville, Quodlibet I, 15, ms. BnF, lat. 16405, fo 33ra-rb; Vatican, lat. 1015, fo 43ra-rb.

115. Cf. G. Constable, Monastic Tithes from their Origins to the Twelfth Century, Cambridge, 1964, p. 19, n. 3: les dîmes, qui avaient existé en Orient, avaient disparu sans laisser de trace; leur réintroduction après la conquête de 1204 fut une cause constante de troubles. En 1219, les non-latins vivant dans l'empire latin de Constantinople furent autorisés à payer le trentième plutôt que le dixième.

116. Ce concept apparaît déjà chez Guillaume d'Auxerre (par exemple dans le chapitre 4 du traité 51, cit. n. 19, p. 1004) et chez Alexandre de Halès (Summa, tit. De decimis, cap. 6, cit. n. 8, p. 742a). L'un et l'autre l'emploient à propos du cas précis des paysans qui versent la dîme à des chevaliers et qui sont excusés par la dissimulatio de l'Église, à condition qu'ils conservent la volonté de la rendre à l'Église si celle-ci la leur demande.

117. Thomas d'Aquin, Quodlibet II, 8, cit. n. 25, p. 226. 
concept qualifiait l'attitude par laquelle l'Église, en s'abstenant de revendiquer son droit, admettait tacitement la validité de la coutume contraire. Thomas d'Aquin le fonde sur l'exemple apostolique de Paul ${ }^{118}$, « qui n'avait pas usé du pouvoir que le Seigneur lui avait donné en sorte qu'il reçoive sa subsistance de ceux auxquels il prêchait l'Évangile » ${ }^{119}$, suivant la première Épître aux Corinthiens $(9,12)$ : « Mais nous n'avons point usé de ce pouvoir; et nous souffrons au contraire toutes sortes d'incommodités pour n'apporter aucun obstacle à l'Évangile de Jésus-Christ ».

\section{$\underline{\text { Justification des dîmes lä̈ques }}$}

Quant au phénomène des dîmes laïques, notamment lié à la pratique de l'inféodation, les théologiens l'ont presque unanimement justifié au moyen d'une distinction entre ius et fructus, empruntée au droit romain par l'intermédiaire des canonistes $^{120}$ et relayée dès le début du XIII ${ }^{\mathrm{e}}$ siècle par certains membres du cercle de Pierre le Chantre. Parmi les canonistes, Huguccio semble être le premier à avoir opéré la distinction entre le ius spirituale exclusivement détenu par l'Église et le ius percipiendi qui autorisait à percevoir les fruits de la dîme et pouvait être concédé à des laïcs. Au milieu du XIII ${ }^{\mathrm{e}}$ siècle, même Hostiensis soutient cette opinion - et après lui Gérard d'Abbeville ${ }^{121}$, quoique en termes moins nets. Hostiensis affirme que « ce droit, parce qu'il est civil, peut être concédé à un laïc, non quant à la propriété, mais quant à la perception des fruits, et à titre temporaire, et non perpétuel ${ }^{122}$. On notera qu'Hostiensis, qui refusait la coutume de ne pas acquitter de dîmes, admet leur concession au titre de la distinction entre proprietas et perceptio fructuum.

La distinction entre droit et revenus excusait, mais dans certaines limites: elle s'appliquait aux seules concessions antérieures au concile de Latran III - qui avait interdit toute nouvelle collation de dîme à des laïcs - et à des chevaliers menant bonne vie et défendant l'Église comme de bons vassaux ${ }^{123}$, suivant les termes employés par Raymond de Peñaforte, repris littéralement par passages par Alexandre de Halès ${ }^{124}$ et suivis par John Peckham dans une détermination quodlibétique de 1270 sur des laïcs qui habent decimas ab antiquo ex concessu

118. Dans les Quodlibets comme dans la Somme.

119. Thomas d'Aquin, Summa theologiae, IIa IIae, q. 87, a. 1, ad $5^{\text {um }}$, cit. n. 33, p. 229.

120. Jean le Teutonique fait explicitement référence au Digeste, 21, 2,43 (TH. MommsEn éd., Digesta Iustiniani Augusti, t. 1, Berlin, 1962, p. 626) dans la Glose ordinaire au Décret de Gratien (Gl. Laicalibus ad Grat. C. 1, q. 3, c. 13, éd. Turin, 1588, col. 682-683).

121. Gérard d'Abbeville, Quodlibet I, 16, ms. BnF, lat. 16405, fos 33rb-va; Vatican, lat. 1015, fos 43rb-va: Dic cum Bernardo quod papa "non dat alicui privilegium de non dandis decimis, sed concedit ei administrationem decimarum, ut inde suscipiat sustentationem et residuum convertat in usum pauperum" [...] Et sic dat ad tempus, ut stipendium, non ut titulus sit, nec in perpetuum nec transitoria ad heredes decima laico potest dari.

122. Hostiensis, Summa aurea, cit. n. 23, $\mathrm{f}^{\circ} 253 \mathrm{ra}$.

123. Raymond de Peñaforte, Summa de paenitentia, lib. 1, tit. 15, cap. 7, cit. n. 66, col. 419.

124. Alexandre de Halès, Summa, tit. De decimis, cap. 6, a. 1, cit. n. 8, p. 741. 
Ecclesiae $^{125}$. Raymond de Peñaforte attribue nommément à Tancrède et à Jean le Teutonique ${ }^{126}$ la distinction qui forme la clé de voûte de sa solution : les dîmes sont dues aux églises en raison du service divin (donc en vertu d'un droit « purement spirituel »); mais elles sont aussi dues « en reconnaissance du pouvoir universel» (donc en vertu d'un droit « civil » ${ }^{127}$ ). Comme le dit Peckham, les revenus (fructus) des dîmes peuvent être concédées à un laïc, défenseur de ce pouvoir universel, quant aux revenus (quoad fructus), dans les limites indiquées ${ }^{128}$.

À distance des juristes, Thomas d'Aquin forge sa propre distinction entre un ius accipiendi decimas qualifié de spirituel et des res quae nomine decimae dantur qualifiées de corporelles. Le ius était dû au ministère de qui semait des spiritualia, donc aux seuls clercs ayant charge d'âmes. En revanche, les res nommées dîmes, étant corporelles, pouvaient être cédées in usum quorumlibet, y compris des laïcs. Comme l'Église pouvait transmettre à un laïc la dîme reçue, elle pouvait aussi lui permettre de la recevoir lui-même, tout en en réservant le droit aux ministres de l'Église, soit pour la nécessité de l'Église (on dit ainsi que des dîmes ont été concédées en fief par l'Église à certains chevaliers), soit pour l'entretien des pauvres (des dîmes ont ainsi été concédées à titre d'aumônes - per modum eleemosynae - « à certains religieux laïcs ou sans charge d'âmes ») ${ }^{129}$.

Le cas limite du chevalier pauvre condense les deux termes de la justification (nécessité de l'Église, entretien des pauvres). Il apparaît dans la Summa de Robert de Courson en 1212-1213, et dans tous ses détails chez Guillaume d'Auxerre:

«Un chevalier a des dîmes pour seul revenu, mais ne veut pas vivre en état de péché mortel; or s'il restitue les dîmes, il n'aura plus de quoi nourrir ses enfants ni sa femme, et peut-être ses filles se prostitueront-elles, ses fils deviendront-ils des voleurs et beaucoup d'autres inconvénients se produiront-ils. Que doit-il faire? [...] Solution: le chevalier doit venir voir l'évêque et lui représenter son indigence, et l'évêque doit lui laisser temporairement les revenus de ces dîmes, pourvu qu'il promette de les rendre à l'Église aussitôt qu'il le pourra. Mais si l'évêque est mauvais (perversus) et refuse de les lui laisser, alors le chevalier doit les rendre: mieux vaut en effet qu'il soit toujours pauvre, plutôt qu'il les détienne en état de péché mortel ${ }^{130}$.

En dernière extrémité, toutes les options casuistiques ayant été épuisées, mieux valait donc laisser sa famille mourir de faim plutôt que s'exposer au risque de péché mortel. Dans sa rigueur, cette solution de Guillaume d'Auxerre fait écho à l'opinion qu'il avait soutenue à propos du vœu dans le traité précédent de la

125. John Peckham, Quodlibet I, 25 (Paris, 1270), éd. G. J. ETZKORN et F. Delorme, dans Quodlibeta quatuor, Grottaferrata, 1989, p. 55.

126. Nommés par Raymond de Peñaforte; Alexandre de Halès évoque les iurisperiti sans plus de précision (Summa, cit. n. 8, p. 740a).

127. Raymond de Peñaforte, Summa de paenitentia, lib. 1, tit. 15, cap. 7, cit. n. 66, col. 418.

128. Que ce laïc vive bien, que les dîmes lui aient été concédées avant le concile de Latran III et qu'il défende l'Église (John Peckham, Quodlibet I, 25, cit. n. 124, p. 56).

129. Thomas d'Aquin, Summa theologiae, IIa IIae, q. 87, a. 3, ad $3^{\text {um }}$, cit. n. 33, p. 232.

130. Guillaume d'Auxerre, lib. 3, tr. 51, cap. 6, cit. n. 19, p. 1010. 
Summa aurea: mieux valait laisser mourir de faim des parents indigents plutôt que s'exposer au risque de péché mortel en retardant, pour pouvoir subvenir à leurs besoins, son entrée en religion ${ }^{131}$.

On observe une autre occurrence du cas du chevalier pauvre chez Raymond de Peñaforte: quelqu'un qui avait reçu ou retenu des dîmes depuis longtemps venait à satisfaction, affirmant qu'il avait péché par ignorance et simplicité, ou alors sciemment, et demandait qu'on lui remît ces dîmes intuitu Dei et eleemosynae, sans quoi lui et sa famille seraient réduits à la mendicité ${ }^{132}$. Raymond de Peñaforte répond que l'Église pouvait réclamer ces dîmes, mais que si elle considérait la contrition et la sincérité des prières de celui qui les détenait, elle devait les lui laisser tamquam pauperi, pour qu'il en vive; ce serait la même chose que si elle les lui donnait ensuite. On notera que, comme Thomas d'Aquin, Raymond de Peñaforte admettait la concession de dîmes à titre d'aumône, alors même qu'il refusait en termes explicites l'exemption des pauvres.

\section{Le cas des religieux: exempts et bénéficiaires}

Suivant Guillaume d'Auxerre et Thomas d'Aquin, deux raisons justifiaient que les religieux soient exemptés, voire bénéficiaires de la dîme: la prestation de spiritualia; un "privilège » ou une «immunité » pontificale. Selon Guillaume d'Auxerre, les Cisterciens jouissaient précisément d'un privilegium issu d'une décision pontificale (ex ordine... domini pape) qui leur permettait d'acheter des terres dans des paroisses et, s'ils les cultivaient eux-mêmes, de ne pas verser de dîme ${ }^{133}$. Quant aux moines noirs, aux Templiers et aux Hospitaliers, ils bénéficient d'une conception extensive de la prestation des spiritualia: les bénédictins qui levaient la dîme n'étaient pas des raptores, car ils semaient des spiritualia per se et per alios: en tant que patrons des églises dont ils avaient institué les prêtres qu'ils devaient pourvoir de bénéfices convenables; par leurs prières et leur prédication propres, assimilées au « soin des âmes » rétribué par la dîme. Les Templiers et les Hospitaliers ne devaient pas être tenus pour des voleurs, mais pour des lévites, car «bien qu'ils ne sèment pas de spiritualia en prêchant, ils en sèment en priant et en servant les prédicateurs. Or sous la Loi ancienne, tous les lévites ne servaient pas à l'autel, et pourtant ils vivaient des dîmes $»^{134}$.

Thomas d'Aquin développe synthétiquement la même opinion ${ }^{135}$, sans nommer aucune famille religieuse ni détailler la façon dont les religieux administraient les spiritualia, et en qualifiant d'« immunité » l'exemption d'origine pontificale ${ }^{136}$.

131. Ibid., lib. 3, tr. 50, cap. 2, p. 978.

132. Raymond de Peñaforte, Summa de paenitentia, lib. 1, tit. 15, cap. 12, cit. n. 66, col. 424.

133. Guillaume d'Auxerre, lib. 3, tr. 51, cap. 4, cit. n. 19, p. 1003.

134. Ibid.

135. Thomas d'Aquin, Summa theologiae, q. 87, a. $3,3^{\text {um }}$ et ad $3^{\text {um }}$, cit. n. 33, p. 232 ; Ibid., a. $4,2^{\text {um }}$ et ad $2^{\text {um }}$, p. 232-233.

136. Ibid., a. $4,2^{\mathrm{um}}$ et ad $2^{\mathrm{um}}$, p. 232-233. 
Alexandre de Halès avait en revanche consacré un article complet à la question $^{137}$. Il y rappelait la règle canonique par des citations explicites des deux décrétales d'Alexandre III $^{138}$ et du canon du concile de Latran IV $^{139}$ que Raymond de Peñaforte avait présentés comme la «vérité » de la position de l'Église, en contrepoint à la multiplicité des dispositions législatives passées ${ }^{140}$ : Cisterciens, Templiers et Hospitaliers étaient soustraits à la dîme des possessions qu'ils cultivaient eux-mêmes, mais la devaient sur les terres qu'ils avaient affermées; les terres qu'ils avaient acquises après le concile de Latran IV étaient grevées des dîmes dues aux églises dont elles dépendaient. Les moines noirs et les chanoines réguliers et séculiers devaient la dîme sur toutes leurs possessions, sauf terres défrichées, jardins et aliments pour le bétail; ils n'en étaient exemptés que par privilège spécial du pape ou par l'effet de la prescription. Alexandre de Halès intègre en outre une objection, notée par Guillaume d'Auxerre ${ }^{141}$, selon laquelle le pape n'avait pas le pouvoir de dispenser de la « loi de Dieu » qui imposait la dîme. Alexandre de Halès répond que l'Église pouvait décider qui devait recevoir ou acquitter quelles dîmes, parce que le précepte des dîmes était un précepte « judiciel » que l'Église pouvait modifier pour cause de nécessité ou d'utilité, et ce d'autant plus que les religieux étaient réputés faire partie de l'ordre des lévites. Quelques limites sont toutefois rappelées dans les termes strictement juridiques ${ }^{142}$ déjà employés par Raymond de Peñaforte: les religieux devaient les dîmes s’ils y avaient été contraints par un accord ou une action en justice; si la paroisse où se trouvaient leurs terres était « énormément lésée »; si, en les acquittant, ils avaient tacitement renoncé à leur privilège.



$* *$

En définitive, les débats sur la dîme qualifient moins les divergences d'opinions scolastiques - qui affectent des points cruciaux, mais qui sont finalement rares que la forme ou la méthode même de l'enquête contradictoire. Sans étouffer la voix discordante de Gérard d'Abbeville, l'harmonie globale des solutions autorise à évoquer les traits saillants d'une opinion commune sur la dîme. L'apport le plus singulier des théologiens semble avoir consisté dans la construction d'une norme chrétienne de la dîme par la déconstruction du précepte vétérotestamentaire: le droit naturel, identifié à la raison et conforté par la référence capitale à l'Épître aux Corinthiens, est substitué à la Loi pour justifier l'obligation indéterminée de

137. Alexandre de Halès, Summa, tit. De decimis, cap. 7, a. 3 (Utrum religiosi teneantur ad decimas), cit. n. 8 , p. $749-750$.

138. Liber Extra, lib. 3, tit. 30, cap. 10-11 (Fr. 559-560).

139. Alexandre de Halès, Summa, tit. De decimis, cap. 7, a. 3, cit. n. 8, p. 750a.

140. Raymond de Peñaforte, Summa de paenitentia, lib. 1, tit. 15, cap. 1, cit. n. 66, col. 412.

141. Guillaume d'Auxerre, lib. 3, tr. 51, cap. 4, cit. n. 19, p. 1002: Et obicitur de privilegio cisterciensium; antequam dominus papa dedisset eis privilegium de non solvendis decimis de terris, quas ipsi colunt, ipsi tenebantur dare decimas ex Lege Dei; sed contra Legem Domini non potuit dominus papa dispensare $[\ldots]$

142. Liber Extra, lib. 3, tit. 30, cap. 3 (Fr. 556) et cap. 9 (Fr. 559); lib. 5, tit. 33, cap. 6 (Fr. 851). 
la dîme ; l'institution par l'Église en renouvelle radicalement l'obligation déterminée. Si l'héritage est mis à distance, il n'est pas renié : la partie morale du précepte vétérotestamentaire est conservée; sa quotité est reconduite par l'Église «pour qu'il y ait quelque consonance » entre l'Ancienne et la Nouvelle Loi. La notion de précepte mixte apparaît à cet égard comme le moyen décisif de légitimer la pérennité de l'obligation générale des dîmes tout en justifiant les variations éventuelles de sa quotité.

Quant aux exceptions, les théologiens en ont traité suivant des cas, des concepts et des distinctions d'origine juridique. La coutume justifie localement les exemptions et les variations de quotité. La distinction entre ius et fructus permet de rendre raison des cas de concession de dîmes à des laïcs, à des religieux ou à des pauvres en fonction des besoins de l'Église ou à titre d'aumône. La contradiction avec le refus unanime d'exemption des pauvres n'est sans doute qu'apparente: ce qui subsiste dans les deux cas, c'est le droit spirituel de l'Église. Exemption et concession de dîmes sont donc bien distinguées. Consommée par la concession de dîmes à des laïcs, la séparation du couple temporalia / spiritualia menace d'autant moins le droit de l'Église que ce droit repose sur une double conception de la dîme comme rétribution du prêtre, mais aussi comme taxation des biens fonciers paroissiaux dont l'universalité est démontrée par l'extension de la dîme aux biens des juifs et aux biens patrimoniaux des clercs.

Enfin, les désaccords et les différences de formulation que révèle l'examen des sources théologiques tiennent à des divergences exégétiques marginales: les maîtres ont cherché dans les Écritures la preuve de la confirmation néotestamentaire de la légalité de la dîme; ceux qui l'y ont trouvée ne forment guère qu'un groupuscule. Les différences d'opinion et de formulation semblent tenir davantage aux rapports que les théologiens ont entretenus avec le droit: on a pu observer la proximité des solutions de Gérard d'Abbeville et d'Hostiensis ou d'Alexandre de Halès et de Raymond de Peñaforte, de même que la place occupée chez Alexandre de Halès par des références juridiques qui sont implicites ou absentes chez Guillaume d'Auxerre ou chez Thomas d'Aquin. Il ne s'agit sans doute pas là d'une simple question de positionnement par rapport aux sources juridiques: les débats sur la dîme montrent que les théologiens ont véritablement investi le territoire des juristes, en élaborant leurs solutions propres à partir des lacunes ou des hésitations du droit et des divergences entre ses commentateurs. La norme théologique sur la dîme s'élabore et se précise ainsi par la prise en charge des cas, des références et des interprétations issus de la théologie comme du droit et par la répétition, la reformulation ou l'amendement des solutions antérieures. 